\title{
ESTADO NUTRICIONAL E PRODUÇÃO DO CAPIM-PÉ-DE-GALINHA E DA SOJA CULTIVADA EM SUCESSÃO EM SISTEMA ANTECIPADO DE ADUB AÇÃO ( $\left.{ }^{1}\right)$
}

\author{
EROS ARTUR BOHAC FRANCISCO $\left({ }^{2 *}\right)$; GIL MIGUEL DE SOUSA CÂMARA $\left({ }^{3}\right)$; \\ CLÁUDIO ROBERTO SEGATELLI $\left({ }^{4}\right)$
}

\begin{abstract}
RESUMO
Argumenta-se sobre a viabilidade de manejo químico do solo estar relacionado à adubação de todo o sistema de cultivo (adubação antecipada) visando promover o incremento de material orgânico no agroecossistema, devido as suas inúmeras vantagens no aspecto da conservação do solo, preservação dos recursos naturais renováveis e na reciclagem dos nutrientes; ou mantém-se o tradicional sistema de adubação de base, isto é, aplicação de fertilizantes simultaneamente à semeadura da cultura. O objetivo deste trabalho foi avaliar o efeito da antecipação da adubação para a cultura da soja sobre: (a) produção de matéria seca e extração de nutrientes pelo capim-pé-de-galinha [Eleusine coracana (L.) Gaertn.] e (b) acúmulo de matéria seca, exportação de nutrientes e produtividade de grãos da cultura da soja semeada em sucessão ao capimpé-de-galinha. O experimento foi desenvolvido em Piracicaba (SP), na safra agrícola 2001/2002, utilizando o delineamento de blocos completos casualizados com três repetições. A antecipação da adubação da soja, por ocasião da semeadura do capim-pé-de-galinha, não interferiu no acúmulo de matéria seca, na exportação de nutrientes pelos grãos, nem na produtividade agrícola da soja. O capim-pé-de-galinha respondeu positivamente à adubação da soja aumentando a produção de matéria seca e a extração de nutrientes. Os resultados deste estudo mostram que o manejo da adubação, visando ao rendimento operacional do processo de semeadura, pode ser utilizado para favorecer a instalação da cultura da soja na época recomendada.
\end{abstract}

Palavras-chave: Eleusine coracana, semeadura direta, planta de cobertura.

\section{ABSTRACT \\ NUTRITIONAL CONDITION AND YIELD OF FINGER MILLET AND SOYBEAN GROWN IN SUCCESSION IN A SYSTEM OF ANTICIPATED FERTILIZATION}

Questions arise on the viability of the chemical management of soil being related to the fertilization of the cropping system (anticipated fertilization) aiming to increase organic matter in agroecosystems due to their several advantages regarding soil conservation, natural resources preservation and nutrient recycling; or whether the traditional fertilization practices should be maintained. The objective of this research was to evaluate the effect of the anticipation of soybean fertilization on: (i) the dry matter yield and nutrients uptake of finger millet, and (ii) the dry matter yield, nutrients exportation, and grain yield of soybean cultivated after finger millet [Eleusine coracana (L.) Gaertn.]. The experiment was carried out in Piracicaba, State of São Paulo, during the 2001/2002 growing season, in a randomized complete blocks design with three replications. The anticipation of the soybean fertilization did not interfere in the dry matter yield, grain yield, and the nutrient exportation by soybean. Finger millet responded to the soybean fertilization increasing its dry matter yield and nutrient uptake. The management of fertilization to adequate the production system and optimize the sowing process performance can be used in order to install the soybean crop in the field within the proper time.

Key words: Eleusine coracana, no-tillage, crop residue.

$\left({ }^{1}\right)$ Recebido para publicação em 23 de fevereiro de 2006 e aceito em 31 de outubro de 2006. Extraído da Dissertação de Mestrado apresentada pelo primeiro autor ao Programa de Pós-graduação em Fitotecnia, ESALQ/ USP, Piracicaba (SP).

$\left({ }^{2}\right)$ ESALQ/USP, Piracicaba (SP). Ex-bolsista CAPES. E-mail: eabfranc@yahoo.com. $\left({ }^{*}\right)$ autor correspondente.

$\left({ }^{3}\right)$ Departamento de Produção Vegetal, ESALQ/USP, Caixa Postal 09, 13418-900 Piracicaba (SP). E-mail:gmscamar@esalq.usp.br.

$\left({ }^{4}\right)$ Doutorando em Fitotecnia, USP/ESALQ, Piracicaba (SP). E-mail: crsegate@esalq.usp.br 


\section{INTRODUÇÃO}

No sistema de semeadura direta (SSD), a cobertura vegetal morta tem papel importante no aspecto da conservação do solo e da reciclagem de nutrientes (WisNiewSKI e Holtz, 1997; SAntos et al., 1998), e por isso, têm-se buscado espécies com elevada produção de matéria seca no período da entressafra. O capim-pé-de-galinha [Eleusine coracana (L.) Gaertn.] foi recentemente introduzido no Brasil como opção para a integração agricultura-pecuária e para cobertura do solo em SSD. Tem sido utilizado em sistemas agrícolas, antecedendo a cultura da soja, nos Estados da região central do Brasil. No entanto, sua utilização é baseada na adaptação de técnicas de cultivo de outras gramíneas.

O E. coracana é uma planta anual, de porte ereto, com altura máxima de $1,65 \mathrm{~m}$ e perfilhamento vigoroso, folhas lanceoladas com até $0,7 \mathrm{~m}$ de comprimento, inflorescência digitada com um ou mais racemos produzindo grãos de coloração branca, vermelha, marrom ou preta, de forma globosa com no máximo 2 mm de comprimento (HILU e DE WET, 1976). O capim-pé-de-galinha, largamente cultivado nas regiões Sul e Leste da África e Sul da Ásia (Hilu e De WET, 1976), tem seus grãos utilizados como farinha na alimentação humana e na alimentação animal (OduORI, 1994). Uma vez que há pouca informação científica a respeito do capim-pé-de-galinha em condições brasileiras, faz-se importante o conhecimento de suas características nutricionais e produtivas.

A consolidação do SSD na Região CentroOeste do país, e o desenvolvimento de materiais genéticos adaptados às diversas regiões brasileiras, tornou indispensável o aprimoramento de métodos de adubação, a fim de acompanhar a constante necessidade de aumento da produtividade, e, com isso, maior taxa de utilização de fertilizantes, cujo consumo saltou de 10,8 milhões de toneladas em 1995 para 20,2 milhões de toneladas em 2005 (ANDA, 2006).

Preconiza-se, e até se observa, de forma insipiente, a adoção da técnica conhecida como "adubação de sistema" ou "adubação antecipada do agroecossistema". Essa técnica consiste na antecipação da aplicação total ou parcial da dose recomendada de fertilizante $\left(\mathrm{kg} \mathrm{ha}^{-1}\right)$, para a cultura de verão, no momento da adubação da cultura antecessora, na forma de adubação a lanço ou incorporada. Dessa forma, também são antecipadas a manipulação e a movimentação dos fertilizantes, o que permite (a) que a operação de semeadura da cultura de verão ocorra de forma mais rápida; (b) o aproveitamento da umidade do solo ideal para o plantio, e (c) a economia de combustível com menor movimentação de máquinas, corroborando para melhorar o rendimento operacional no processo de instalação da lavoura, visto que o fator determinante para obtenção de elevada produtividade na cultura da soja é a semeadura em época recomendada, pois o desenvolvimento da planta é influenciado pela variação do fotoperíodo e da temperatura (CÂMARA, 1991; Lima et al., 2000; Реiхото et al, 2000). Logo, um sistema de produção em que se verifique economia tempo dispendido para o abastecimento da semeadora-adubadora, com base na redução da dose de fertilizante aplicado, conseguirá maior pontualidade no processo de semeadura.

Outra vantagem da adubação antecipada na cultura antecessora para a formação de palhada visando à semeadura direta reside no incremento de matéria orgânica para o agroecossistema, melhorando a conservação do solo, a manutenção de umidade e a reciclagem de nutrientes, que via mineralização da matéria orgânica, vão passar às formas disponíveis à cultura de verão em sucessão (Silva e Rosolem, 2001).

O objetivo deste trabalho foi avaliar o efeito da antecipação da adubação para a cultura da soja sobre: (a) a produção de matéria seca e extração de nutrientes pelo capim-pé-de-galinha e (b) a produção de matéria seca, exportação de nutrientes e produtividade de grãos da cultura da soja semeada em sucessão ao capim-pé-de-galinha.

\section{MATERIAL E MÉTODOS}

A pesquisa foi desenvolvida no ano agrícola 2001/2002 no município de Piracicaba (SP), latitude $22^{\circ} 50^{\prime}$ sul e longitude $48^{\circ} 01^{\prime}$ oeste. O experimento foi realizado sobre Latossolo Amarelo distrófico (EMBRAPA, 1999b), textura média, anteriormente cultivado com a cultura do milho, com as seguintes características químicas e granulométricas na camada arável $(0-20 \mathrm{~cm}): \mathrm{pH}\left(\mathrm{CaCl}_{2}\right)$ 5,4; $\mathrm{P}$ resina, 6 $\mathrm{mg} \mathrm{dm}{ }^{-3} ; \mathrm{H}+\mathrm{Al}, 22 \mathrm{mmol}_{\mathrm{c}} \mathrm{dm}^{-3} ; \mathrm{K}, 1,9 \mathrm{mmol}_{\mathrm{c}} \mathrm{dm}^{-3}$; Ca, $22 \mathrm{mmol}_{\mathrm{C}} \mathrm{dm}^{-3} ; \mathrm{Mg}, 15 \mathrm{mmol}_{\mathrm{c}} \mathrm{dm}^{-3}$; CTC, 60,9 $\mathrm{mmol}_{\mathrm{c}} \mathrm{dm}^{-3} ; \mathrm{V}, 64 \% ; \mathrm{m}, 3 \% ; 720 \mathrm{~g} \mathrm{~kg}^{-1}$ de areia; $80 \mathrm{~g}$ $\mathrm{kg}^{-1}$ de silte e $200 \mathrm{~g} \mathrm{~kg}^{-1}$ de argila. A recomendação de adubação da soja correspondeu a $90 \mathrm{~kg} \mathrm{ha}^{-1}$ de $\mathrm{P}_{2} \mathrm{O}_{5}$ e $50 \mathrm{~kg} \mathrm{ha}^{-1}$ de $\mathrm{K}_{2} \mathrm{O}$, aplicados na forma de superfosfato triplo e cloreto de potássio, respectivamente, e da aplicação via foliar, aos 30 e 45 dias após a emergência, dos micronutrientes Co e Mo, na dose de $150 \mathrm{~mL} \mathrm{ha}^{-1}$ do produto comercial (Co: 3,825 $\mathrm{g} \mathrm{ha}^{-1}$; Mo: 38,25 $\mathrm{g} \mathrm{ha}^{-1}$ ) e B, Cu, Mn, e Zn, na dose de $2 \mathrm{~L} \mathrm{ha}^{-1}$ do produto comercial (B: 12,6 g $\mathrm{ha}^{-1}$; Cu: 12,6 $\mathrm{g} \mathrm{ha}^{-1}$; Mn: 75,6 $\mathrm{g} \mathrm{ha}^{-1}$; Zn: $126 \mathrm{~g} \mathrm{ha}^{-1}$ ) (Mascarenhas e TANAKa, 1997). 
O experimento foi instalado em delineamento de blocos casualizados, com três repetições. Os tratamentos consistiram da antecipação total ou parcial da adubação da soja para o capim-pé-degalinha, compondo-se do seguinte: T1, adubação recomendada (AR) efetuada na semeadura da soja; T2, $100 \%$ do P da AR aplicados na semeadura do capimpé-de-galinha (CPG); T3, $100 \%$ do K da AR aplicados na semeadura do CPG; T4, 50\% do P e do K da AR aplicados na semeadura do CPG; T5, adubação recomendada efetuada na semeadura do CPG; T6, controle (sem adubação em ambas as culturas).

Realizou-se a análise da variância dos dados de extração de nutrientes e produção de matéria seca do capim e da produção de matéria seca (para cada estádio fenológico amostrado), exportação de nutrientes e produtividade da soja. As médias foram comparadas entre si pelo teste de Duncan a 5\%.

Antes da semeadura do capim-pé-de-galinha, promoveu-se a adubação, a lanço, das parcelas experimentais conforme os tratamentos (T2, T3, T4 e T5). O capim Eleusine coracana (L.) Gaertn., cultivar ANSB Pé-de-galinha 5352, foi semeado na primeira semana de setembro utilizando-se $10 \mathrm{~kg} \mathrm{ha}^{-1} \mathrm{de}$ sementes, misturadas a $0,12 \mathrm{~m}^{3}$ de areia seca ao ar, aplicadas a lanço e incorporadas com grade niveladora. Aos 20 dias após a emergência, aplicouse a dose de $30 \mathrm{~kg} \mathrm{ha}^{-1}$ de nitrogênio (uréia) em todas as parcelas, com área total de $108 \mathrm{~m}^{2}(9 \times 12 \mathrm{~m})$. Foi realizada a irrigação da área experimental até o ponto de dessecação do capim. Aos 75 dias após a emergência, no estádio de pleno florescimento das plantas, realizou-se a amostragem da parte aérea do capim-pé-de-galinha, mediante coleta de $0,5 \mathrm{~m}^{2}$ de área de cada parcela, e em seguida, o manejo de dessecação com herbicida. O material coletado foi seco em estufa a $65^{\circ} \mathrm{C}$, até massa constante, pesado e a concentração dos nutrientes em amostras do tecido moído da parte aérea foi determinada de acordo com método descrito por EMBRAPA (1999a).

Previamente à semeadura da soja, realizou-se a adubação das parcelas, conforme os tratamentos (T1, $\mathrm{T} 2$, T3 e T4), em sulcos de $15 \mathrm{~cm}$ de profundidade e distantes $50 \mathrm{~cm}$ abertos manualmente. A cultivar BRS133 foi semeada com semeadora de parcelas na primeira semana de dezembro à taxa de 20 sementes por metro linear. As sementes de soja foram submetidas ao tratamento com fungicida e, posteriormente, à inoculação com inoculante turfoso (em dose correspondente a 600.000 células de Bradirrizóbios por semente). O cultivo da soja foi realizado sem irrigação e efetuado o manejo fitossanitário para o controle de pragas e doenças. Coletaram-se amostras para determinação da produção de matéria seca nos estádios fenológicos $\mathrm{V}_{4}$ (3. ${ }^{\circ}$ trifólio aberto); $\mathrm{V}_{7}\left(6 .^{\circ}\right.$ trifólio aberto); $\mathrm{V}_{10} / \mathrm{R}_{2}$ (9. ${ }^{\circ}$ trifólio aberto e maioria dos rácemos com flores abertas); $R_{3}$ (vagens com até $0,5 \mathrm{~cm}$ ); $R_{5.3}$ (maioria das vagens com mais de $25 \%$ e até $50 \%$ de granação); $R_{6}$ (maioria das vagens com sementes em volume máximo e plantas verdes) e $R_{7.2}$ (mais de $50 \%$ e até $75 \%$ de folhas e vagens amarelas), tomando-se 10 plantas de cada parcela. A amostragem das plantas foi realizada com pá de corte na profundidade de $40 \mathrm{~cm}$ e as raízes separadas da terra com auxílio de água corrente. As plantas de soja coletadas foram separadas em raiz, caule, folhas e vagens (quando presentes), e secas em estufa a $65^{\circ} \mathrm{C}$ até massa constante. Uma amostra dos grãos de soja na colheita foi separada e encaminhada para análise laboratorial para avaliar a concentração de nutrientes, de acordo com método descrito por EMBRAPA (1999a).

Os valores médios de matéria seca total produzida em cada estádio fenológico foram plotados em gráfico e ajustada a uma equação polinomial, $Y=$ $a x^{3}+b x^{2}+c x+d$, sendo $Y$ a produção de matéria seca e $x$ o número de dias após a emergência (DAE), para o cálculo dos pontos de inflexão e de máximo da curva. A associação da produção de matéria seca com a escala fenológica da cultura da soja permite a melhor observação do desempenho da planta.

Os valores de precipitação pluvial foram obtidos com a coleta diária do volume de chuva captado em um pluviômetro $\left(100 \mathrm{~cm}^{2}\right.$ de área $)$ posicionado junto à área experimental, enquanto os valores de temperatura média do ar foram extraídos do banco de dados da estação meteorológica do Departamento de Ciências Exatas, da ESALQ/USP, em Piracicaba (SP) (Figura 1).

\section{RESULTADOS E DISCUSSÃO}

\subsection{Concentração, extração de nutrientes e produção de matéria seca do capim-pé-de-galinha}

A produção de MS do capim aumentou com a aplicação de fertilizantes sendo o maior valor observado quando a adubação recomendada para a cultura da soja foi antecipada totalmente para a semeadura do CPG, tratamento $5\left(6.375 \mathrm{~kg} \mathrm{ha}^{-1}\right)$, e os menores valores nos tratamentos ( 1 e 6 ) em que não se aplicou fertilizantes na sua semeadura (Tabela 1). Esses valores estão abaixo dos apresentados por Subba Rao e PrabHu (1996), que obtiveram de 8.000 a $12.000 \mathrm{~kg} \mathrm{ha}^{-1}$ de MS com a aplicação de 100 e $50 \mathrm{~kg}$

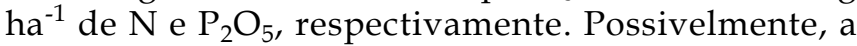
aplicação de $30 \mathrm{~kg} \mathrm{ha}^{-1}$ de $\mathrm{N}$, neste estudo, tenha limitado a produção de MS. 


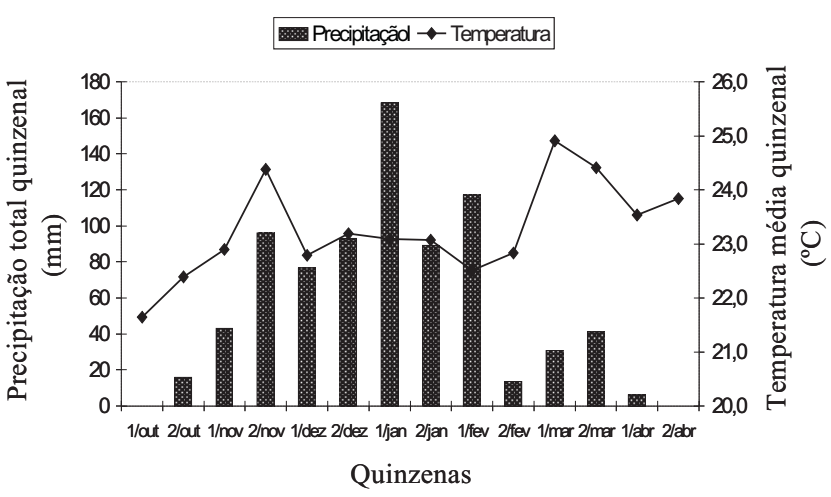

Figura 1. Valores médios de precipitação pluvial total e temperatura média do ar observados na área experimental, para as quinzenas correspondentes ao período de outubro de 2001 a abril de 2002.

A análise dos dados mostrou resposta da concentração de alguns nutrientes ao fator avaliado (Tabela 1). A absorção de $\mathrm{N}$ foi equivalente para todos os tratamentos, e a concentração média encontrada (19,5 $\mathrm{g} \mathrm{kg}^{-1}$ ) foi superior à apresentada por REDDY et al. (1986) de $6,3 \mathrm{~g} \mathrm{~kg}^{-1}$. A aplicação de $30 \mathrm{~kg} \mathrm{ha}^{-1}$ de $\mathrm{N}$ em todos os tratamentos pode ter propiciado a homogeneidade das médias encontradas. A concentração de P na parte aérea das plantas de capim apresentou diferença entre os tratamentos, sendo maior naqueles que receberam $P$ da adubação antecipada. Rossi e Monteiro (1999) observaram acréscimo na concentração de fósforo na parte aérea de capim-braquiária, em vista da aplicação de doses crescentes do elemento. Os autores comentam que houve correlação entre a produção de matéria seca, a concentração e o acúmulo de fósforo na planta. De acordo com WERNER (1986), o fósforo desempenha importante papel no desenvolvimento do sistema radicular e no perfilhamento das gramíneas.

Observou-se diferença estatística na concentração de $\mathrm{K}$ na parte aérea do capim, sendo maior nos tratamentos que não receberam aplicação de fertilizante potássico da adubação antecipada (1, 2,4 e 6) e menor naqueles que foram adubados ( 3 e 5 ) e com elevada produção de matéria seca. Esse fato está associado ao efeito de diluição da concentração do elemento causado pela maior quantidade de MS produzida. A concentração de cálcio na parte aérea das plantas de capim-pé-de-galinha foi diferente entre os tratamentos e esteve associada à concentração de P. Possivelmente, o cálcio presente no superfosfato triplo, utilizado como fonte de $\mathrm{P}$, também foi absorvido em maior quantidade. Todavia, a maior absorção de fósforo poderia favorecer o crescimento radicular, com mais energia, promovendo a exploração de maior volume de solo e a maior absorção de cálcio. As concentrações de magnésio e enxofre não foram alteradas em função dos tratamentos empregados.

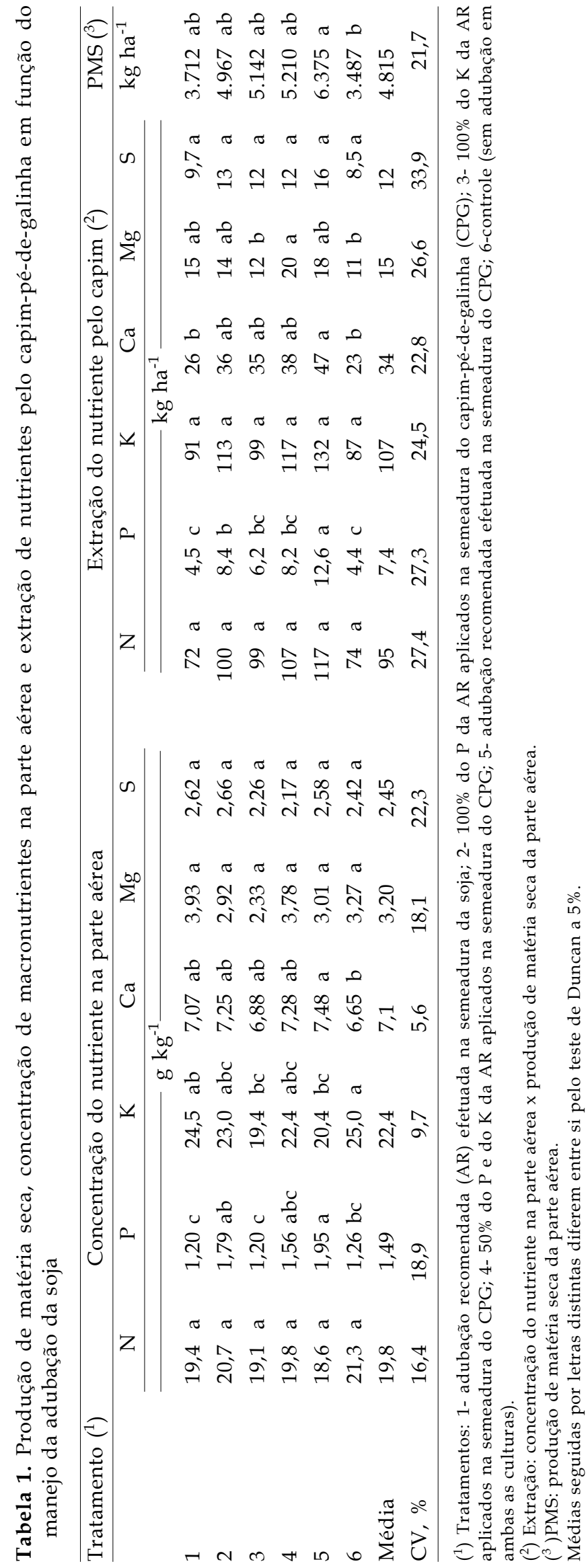


O capim-pé-de-galinha extraiu do solo em média ( $\mathrm{kg} \mathrm{t}^{-1}$ de MS) 19,8; 1,5; 22,5; 7,1;3,2 e 2,5 kg de N, P, K, Ca, Mg e S (Tabela 1). Moraes (2001), estudando a quantidade de nutrientes extraídos pelo sorgo e milheto, observa valores médios de extração de $\mathrm{N}$ e K da ordem de 12,8 e 15,5 $\mathrm{kg} \mathrm{t}^{-1}$ de MS, respectivamente, para ambas as culturas. Os valores de $\mathrm{N}$ e K extraídos pelo capim-pé-de-galinha neste estudo (19,8 e 22,5 kg $\mathrm{t}^{-1}$ de $\mathrm{N}$ e $\mathrm{K}$, respectivamente) foram superiores aos obtidos por aquele autor (Tabela 1). Com base nos resultados obtidos, constatou-se que a ordem decrescente da média de macronutrientes extraídos pela cultura do capim-pé-de-galinha, em kg ha- ${ }^{-1}$, foi: $\mathrm{K}(109,5)>\mathrm{N}(93,4)>\mathrm{Ca}(34,7)>\mathrm{Mg}(15,75)>\mathrm{S}(11,6)$ $>\mathrm{P}(7,7)$.

\subsection{Produção de matéria seca pela cultura da soja}

Em nenhum dos estádios fenológicos avaliados houve diferença na produção de matéria seca das plantas de soja (Tabela 2). O acúmulo de matéria seca pelas plantas mostrou valores crescentes ao longo do ciclo da cultura, atingindo o ponto máximo no estádio $\mathrm{R}_{6}$, com $911 \mathrm{~g} \mathrm{~m}^{-2}$ de MS, correspondente a $9.110 \mathrm{~kg} \mathrm{ha}^{-1}$, e mantendo-se estável até o estádio $R_{7.2}$ (Tabela 3 ). Através da curva ajustada aos dados de matéria seca, foi possível calcular os pontos de inflexão e de máximo para a cultura (Figura 2). O ponto de máximo acúmulo de MS ocorreu aos $98 \mathrm{DAE}$, com o valor teórico de $942,9 \mathrm{~g} \mathrm{~m}^{-2}$, o que representou, aproximadamente, $45 \mathrm{~g}$ por planta. Esse valor foi próximo ao observado por PEDRINHO JÚNIOR et al. (2004) de $35 \mathrm{~g}$ por planta. O ponto de inflexão, que pode ser entendido como o dia em que o acúmulo diário de MS chegou a seu valor máximo, ocorreu aos $52 \mathrm{DAE}$ (entre os estádios $R_{3}$ e $R_{5.3}$ ), com o valor teórico de $15,34 \mathrm{~g} \mathrm{~m}^{-2}$, semelhante ao observado por Hanway e Weber (1971).

A análise dos dados de produção de matéria seca das partes da planta (raiz, caule, folhas e vagens) não detectou diferença com os tratamentos empregados. Observa-se na figura 2, a distribuição de MS para as diferentes estruturas da planta (reprodutivas e vegetativas). O acúmulo de MS em estruturas reprodutivas da soja se iniciou ao redor dos 50 DAE e manteve crescimento constante até o estádio $\mathrm{R}_{7.2}$, quando atingiu cerca de $55 \%$ do total. Nos primeiros 50 DAE da cultura da soja, a maior quantidade de MS foi alocada nas folhas, que representaram cerca de $53 \%$ do total, enquanto raízes e caules cerca de $11 \%$ e $33 \%$, em média, respectivamente, o que está de acordo com o obtido por Mascarenhas (1972). Após esse período, todas as estruturas vegetativas da planta demonstraram decréscimo no acúmulo de matéria seca total e finalizaram o ciclo da cultura com 14, 23 e $8 \%$, de folhas, caules e raízes respectivamente. Esses dados estão de acordo com os apresentados por Pedrinho Júnior et al. (2004) e Hanway e Weber (1971).

Os valores médios para o acúmulo de MS total obtidos para cada estádio fenológico foram: $71 \mathrm{~g} \mathrm{~m}^{-2}$ $\mathrm{dia}^{-1} \mathrm{em} \mathrm{V}_{7} ; 135 \mathrm{~g} \mathrm{~m}^{-2} \mathrm{dia}^{-1} \mathrm{em} \mathrm{V}_{10} / \mathrm{R}_{2} ; 149 \mathrm{~g} \mathrm{~m}^{-2} \mathrm{dia}^{-}$ ${ }^{1} \mathrm{em} \mathrm{R}_{3} ; 156 \mathrm{~g} \mathrm{~m}^{-2} \mathrm{dia}^{-1} \mathrm{em} \mathrm{R}_{5.3}$; e $128 \mathrm{~g} \mathrm{~m}^{-2} \mathrm{dia}^{-1} \mathrm{em}$ $\mathrm{R}_{6}$. Регхото et al. (1998) obtiveram, para a cultivar IAC-17, um valor máximo para o acúmulo de MS total de $174 \mathrm{~g} \mathrm{~m}^{-2} \mathrm{dia}^{-1}$, aos 53 DAE.

Tabela 2. Valores médios de produção de matéria seca de plantas de soja, cultivar BRS-133, cultivadas sobre a palhada de Eleusine coracana (L.) Gaertn., observados nos estádios fenológicos $V_{4}, V_{7}, V_{10} / R_{2}, R_{3}, R_{5.3}, R_{6}$ e $R_{7.2}$

\begin{tabular}{|c|c|c|c|c|c|c|c|}
\hline \multirow{2}{*}{ Tratamento $\left({ }^{1}\right)$} & \multicolumn{7}{|c|}{ Estádios fenológicos } \\
\hline & V4 & V7 & $\mathrm{V} 10 / \mathrm{R} 2$ & R3 & $\mathrm{R}_{5.3}$ & $\mathrm{R}_{6}$ & $\mathrm{R}_{7.2}$ \\
\hline & & & $x^{2}+x^{2}$ & $\mathrm{~g} \mathrm{~m}^{-2}$ & & & \\
\hline 1 & 37 & 132 & 276 & 554 & 575 & 852 & 1.177 \\
\hline 2 & 44 & 152 & 360 & 502 & 858 & 987 & 976 \\
\hline 3 & 41 & 140 & 314 & 452 & 710 & 841 & 831 \\
\hline 4 & 42 & 118 & 334 & 525 & 795 & 1.092 & 927 \\
\hline 5 & 40 & 146 & 369 & 574 & 743 & 933 & 902 \\
\hline 6 & 42 & 123 & 306 & 537 & 719 & 795 & 811 \\
\hline Médias & 41 & 135 & 326 & 524 & 733 & 911 & 937 \\
\hline$P>F$ & ns & ns & ns & ns & ns & ns & ns \\
\hline $\mathrm{CV}, \%$ & 16,3 & 20,1 & 16,1 & 18,8 & 26,2 & 25,6 & 22,9 \\
\hline
\end{tabular}

$\left({ }^{1}\right.$ )Tratamentos: 1- adubação recomendada (AR) efetuada na semeadura da soja; $2-100 \%$ do P da AR aplicados na semeadura do capim-péde-galinha (CPG); 3- 100\% do K da AR aplicados na semeadura do CPG; 4- 50\% do P e do K da AR aplicados na semeadura do CPG; 5adubação recomendada efetuada na semeadura do CPG; 6- controle (sem adubação em ambas as culturas). ns = não significativo para análise da variância. 

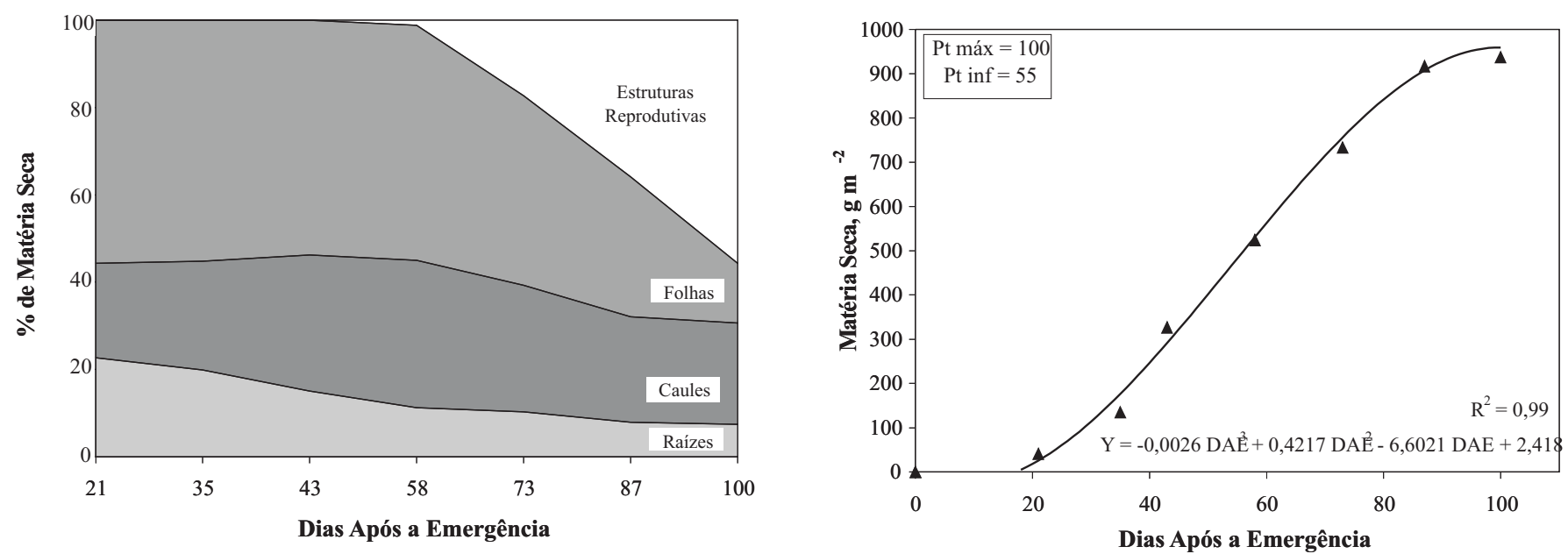

Figura 2. Percentual de matéria seca distribuída em raízes, caules, folhas e estruturas reprodutivas ao longo do ciclo de desenvolvimento e curva de produção de matéria seca total para soja obtida com os valores médios observados em cada estádio fenológico.

Através dos dados da figura 2 e da tabela 3, pôde-se calcular o acúmulo de matéria seca no caule com valores de 19,48 e $56 \mathrm{~kg} \mathrm{ha}^{-1} \mathrm{dia}^{-1}$ entre os estádios de $V_{4}$ a $V_{7}$, de $V_{7}$ a $V_{10} / R_{2}$ e de $V_{10} / R_{2}$ a $R_{3}$ respectivamente. O caule atingiu $48 \%$ de sua massa final no estádio $R_{2}$. Após este estádio o acúmulo de MS é reduzido, caindo para $28 \mathrm{~kg} \mathrm{ha}^{-1} \mathrm{dia}^{-1} \mathrm{em} \mathrm{R}_{5.3}$, e 3,5 $\mathrm{kg} \mathrm{ha}^{-1} \mathrm{dia}^{-1}$ em $\mathrm{R}_{6}$. O ponto de maior acúmulo de matéria seca ocorreu no estádio $R_{6}$, com massa de $0,220 \mathrm{~kg} \mathrm{~m}^{-2}$, mantendo-se estável até o fim do ciclo. Nas raízes também houve ponto de maior acúmulo de matéria seca no estádio $R_{5.3}$, com $0,075 \mathrm{~kg} \mathrm{~m}^{-2}$. Nos estádios seguintes houve redução na massa das raízes. As vagens tiveram acréscimo de massa bastante acelerado, com acúmulos de MS de $88 \mathrm{~kg}$ ha $^{-1}$ dia $^{-1}$, durante o estádio $R_{5.3}, 147 \mathrm{~kg} \mathrm{ha}^{-1} \mathrm{dia}^{-1}$, no estádio $\mathrm{R}_{6}$, e $129 \mathrm{~kg} \mathrm{ha}^{-1} \mathrm{dia}^{-1}$ no final do ciclo, em $R_{7.2}$. Esses dados são condizentes com os apresentados por MASCARENHAS (1973).

Tabela 3. Valores médios de matéria seca produzida em folhas, caules, raízes e vagens de soja, cultivar BRS-133, cultivada sobre a palhada de Eleusine coracana (L.) Gaertn., observados nos estádios fenológicos $\mathrm{V}_{4}, \mathrm{~V}_{7}$, $\mathrm{V}_{10} / \mathrm{R}_{2}, \mathrm{R}_{3}, \mathrm{R}_{5.3}, \mathrm{R}_{6}$ e $\mathrm{R}_{7.2}$

\begin{tabular}{lccccccc}
\hline \multirow{2}{*}{ Órgãos } & \multicolumn{7}{c}{ Estádios Fenológicos } \\
\cline { 2 - 8 } & $\mathrm{V}_{4}$ & $\mathrm{~V}_{7}$ & $\mathrm{~V}_{10} / \mathrm{R}_{2}$ & $\mathrm{R}_{3}$ & $\mathrm{R}_{5.3}$ & $\mathrm{R}_{6}$ & $\mathrm{R}_{7.2}$ \\
\cline { 2 - 8 } Folhas & 22 & 75 & 175 & 282 & 318 & 293 & 128 \\
Caules & 9 & 33 & 102 & 177 & 213 & 222 & 217 \\
Raízes & 9 & 27 & 49 & 59 & 75 & 72 & 69 \\
Vagens & - & - & - & 5 & 126 & 329 & 522 \\
Total & 40 & 135 & 326 & 523 & 732 & 916 & 936 \\
$P>\mathrm{F}$ & $\mathrm{ns}$ & $\mathrm{ns}$ & $\mathrm{ns}$ & $\mathrm{ns}$ & $\mathrm{ns}$ & $\mathrm{ns}$ & $\mathrm{ns}$ \\
$\mathrm{CV}, \%$ & 15,9 & 21,0 & 16,0 & 18,5 & 25,7 & 25,6 & 23,2 \\
\hline
\end{tabular}

\subsection{Exportação de nutrientes e produtividade da soja}

A análise dos dados de exportação de nutritentes indicou diferença estatística entre os tratamentos para N, P e Ca (Tabela 4). Para o nitrogênio, apenas o tratamento 5, que se antecipou totalmente à adubação da soja para o capim, diferiu do tratamento-controle (6), ocorrendo o inverso para o cálcio. Já os tratamentos 1, 4 (sem antecipação da adubação e $50 \%$ do P e K antecipados para o capim respectivamente) e 5 foram superiores ao tratamentocontrole (6) quanto à quantidade de $\mathrm{P}$ exportada pelos grãos de soja. Possivelmente, a diferença entre os tratamentos para $\mathrm{N}$ e $\mathrm{P}$ pode estar associada às quantidades desses elementos extraídas pelo capim (Tabela 1) e disponibilizadas através da decomposição da palhada. Não há trabalhos científicos que demonstrem a liberação de nutrientes pela decomposição da palhada do capim-pé-de-galinha, contudo, WisNIEWSKI e HolTz (1997) observaram que a taxa de decomposição da palhada de milho (gramínea com elevada relação $\mathrm{C} / \mathrm{N}$ ) foi de $50 \%$ e $77 \%$ para $\mathrm{Ne}$ $\mathrm{P}$, respectivamente, no fim de cem dias. É possível que a decomposição da palhada do capim, embora não mensurada neste estudo, tenha disponibilizado $\mathrm{N}$ e $\mathrm{P}$ ao longo do ciclo da soja. No entanto, a inversão ocorrida para o cálcio seria devido a sua função de constituinte estrutural do tecido vegetal desfavorecendo sua liberação por decomposição.

A quantidade de nutrientes extraída pelos grãos de soja apresentou a seguinte ordem decrescente: $\mathrm{N}>\mathrm{K}$ $>\mathrm{P}>\mathrm{S}>\mathrm{Mg}>\mathrm{Ca}$ (Tabela 4). Comparando-se as médias de exportação de nutrientes por tonelada de grãos, obtidas neste trabalho com os valores de TANAKA e MASCARENHAS (1992) para cinco cultivares de soja, pode-se constatar que a cultivar BRS-133 exportou maiores quantidades de $\mathrm{N}$ e $\mathrm{S}$, menores de $\mathrm{P}$ e similares de $\mathrm{K}, \mathrm{Ca}$ e Mg. 
Tabena 4. Produção de grãos e exportação de nutrientes pela soja em função do manejo da adubação

\begin{tabular}{|c|c|c|c|c|c|c|c|}
\hline \multirow{2}{*}{ Tratamento $\left({ }^{1}\right)$} & \multicolumn{6}{|c|}{ Exportação de nutrientes pela soja } & \multirow{2}{*}{ Produção de grãos } \\
\hline & $\mathrm{N}$ & $\mathrm{P}$ & $\mathrm{K}$ & $\mathrm{Ca}$ & $\mathrm{Mg}$ & S & \\
\hline & \multicolumn{6}{|c|}{ kg por tonelada de grãos } & $\mathrm{kg} \mathrm{ha}^{-1}$ \\
\hline 1 & $64 \mathrm{ab}$ & 5,1 a & 16,8 a & $1,5 \mathrm{ab}$ & $2,0 \mathrm{a}$ & $2,1 \mathrm{a}$ & $3.550 \mathrm{ab}$ \\
\hline 2 & $65 \mathrm{ab}$ & $4,7 \mathrm{ab}$ & 15,8 a & $1,5 \mathrm{ab}$ & $2,0 \mathrm{a}$ & $2,2 \mathrm{a}$ & 3.599 a \\
\hline 3 & $65 \mathrm{ab}$ & $4,6 \mathrm{ab}$ & 16,3 a & $1,6 \mathrm{ab}$ & $2,0 \mathrm{a}$ & $2,2 \mathrm{a}$ & $3.479 \mathrm{ab}$ \\
\hline 4 & $66 \mathrm{ab}$ & 4,9 a & 15,8 a & $1,4 \mathrm{ab}$ & $1,9 \mathrm{a}$ & $2,3 \mathrm{a}$ & 3.578 a \\
\hline 5 & 71 a & 4,7 a & 15,8 a & $1,3 \mathrm{~b}$ & $2,0 \mathrm{a}$ & $2,5 \mathrm{a}$ & $3.402 \mathrm{ab}$ \\
\hline 6 & $63 \mathrm{~b}$ & $3,9 \mathrm{~b}$ & 15,8 a & 1,6 a & $1,8 \mathrm{a}$ & $2,2 \mathrm{a}$ & $3.354 \mathrm{~b}$ \\
\hline Média & 66 & 4,6 & 16,1 & 1,5 & 1,9 & 2,2 & 3.494 \\
\hline$C V, \%$ & 5,5 & 8,5 & 5,2 & 8,5 & 7,2 & 9,7 & 3,2 \\
\hline
\end{tabular}

$\left({ }^{1}\right)$ Tratamentos: 1- adubação recomendada (AR) efetuada na semeadura da soja; 2- 100\% do P da AR aplicados na semeadura do capim-péde-galinha (CPG); 3- 100\% do K da AR aplicados na semeadura do CPG; 4- 50\% do P e do K da AR aplicados na semeadura do CPG; 5adubação recomendada efetuada na semeadura do CPG; 6- controle (sem adubação em ambas as culturas).

Médias seguidas por letras distintas diferem entre si pelo teste de Duncan a 5\%.

Para a variável produção de grãos de soja, detectou-se que os tratamentos 2 e 4 foram melhores que o tratamento-controle (Tabela 4), com, em média, a diferença superior de $245 \mathrm{~kg}$ de grãos produzidos. MASCARENHAS et al. (1981) avaliaram a resposta da produção da soja ao efeito residual da adubação de culturas anteriores (milho, algodão e trigo) em diversos ensaios no Estado de São Paulo e demonstraram que a soja caracterizava-se por aproveitar os nutrientes aplicados em anos anteriores ou as quantidades disponíveis no solo, principalmente $\mathrm{P}$ e K. Os autores concluíram que não havia necessidade de adubação da soja quando cultivada em rotação após uma cultura adequadamente adubada. Essa característica da cultura pode estar associada aos resultados obtidos com os tratamentos 2 e 4 , nos quais a dose de $\mathrm{P}$ recomendada foi totalmente e as doses de P e $\mathrm{K}$ foram parcialmente antecipadas para o capim, respectivamente. Possivelmente, a liberação do $P$ e K pela decomposição gradativa da palhada do capim e a redução do efeito salino, provocado sobre as sementes pelas altas doses de K no plantio, foram fatores determinantes para a boa produção de grãos de soja.

O volume total de precipitação pluvial durante os 121 dias do ciclo cultural da soja foi de $637 \mathrm{~mm}$ (Figura 1). Fageria et al. (1997) comentam que o uso da água pela soja pode oscilar entre 450 e $825 \mathrm{~mm}$ onde a estação de crescimento variar de 100 dias, em baixas altitudes, a 190 dias, em elevadas altitudes. Apesar de ter havido um período de decréscimo na precipitação pluvial entre a segunda quinzena de fevereiro e a primeira quinzena de março, não foi necessário realizar a irrigação da área experimental, pois o solo estava úmido.

\section{CONCLUSÕES}

1. A aplicação da adubação da soja aumenta a produção de matéria seca e o acúmulo dos nutrientes pelo capim-pé-de-galinha. Observa-se no acúmulo de nutrientes na matéria seca produzida, a seguinte seqüência: $K>N>$ $\mathrm{Ca}>\mathrm{Mg}>\mathrm{S}>\mathrm{P}$.

2. A antecipação da adubação da soja para o capim-pé-de-galinha não interfere na produção de matéria seca das plantas de soja em nenhum dos estádios fenológicos avaliados.

3. A produtividade da soja é superior quando $100 \%$ da dose de P e $50 \%$ das doses de P e K da adubação da soja são antecipadas para o capim em relação a quando não se aplicou fertilizante em nenhuma das culturas. A produtividade da soja naquelas condições assemelha-se ao tratamento cuja adubação da soja não se antecipou.

4. A antecipação da adubação da soja para o capim-pé-de-galinha não altera a quantidade dos macronutrientes exportados pelos grãos de soja em comparação.

5. O manejo de antecipação da adubação da soja visando aumentar o rendimento operacional do processo de semeadura, com a redução da quantidade de fertilizante aplicada no plantio e conseqüente ganho de pontualidade na instalação da lavoura, não prejudica a nutrição da planta e a produtividade de grãos. 


\section{AGRADECIMENTOS}

Os autores expressam seus agradecimentos ao Departamento de Genética da ESALQ/USP pela concessão da área experimental para realização deste trabalho, à Empresa AgroNorte Pesquisa e Sementes (Sinop-MT) pela doação da semente do capim-pé-degalinha e à Coordenadoria para Aperfeiçoamento de Pessoal de Nível Superior (CAPES) pela concessão da bolsa de estudos do primeiro autor.

\section{REFERÊNCIAS}

ANDA. Associação Nacional para Difusão de Adubos. Disponível em: http://www.anda.org.br/portug/ estatisticas_2005.pdf. Acesso em: 21 julho 2006.

BATAGLIA, O.C.; MASCARENHAS, H.A.A.; TEIXEIRA, J.P.F.; TISSELI FILHO, O. Acúmulo de matéria seca e nutrientes em soja cultivar Santa-Rosa. Bragantia, Campinas, v.35, n.21, p.237248,1976 .

CÂMARA, G.M.S. Efeito do fotoperíodo e da temperatura no crescimento, florescimento e maturação de cultivares de soja (Glycine max (L.) Merrill). 1991. 266f. Tese (Doutorado em Agronomia) - Universidade Federal de Viçosa, Viçosa, 1991.

EMBRAPA. Manual de análises químicas de solos, plantas e fertilizantes. Rio de Janeiro: EMBRAPA, 1999a. 372p.

EMBRAPA. Sistema brasileiro de classificação de solos. Brasília: Embrapa-SPI; Rio de Janeiro: Embrapa-CNPS, 1999b. 412p.

FAGERIA, N.K.; BALIGAR, V.C.; JONES, C.A. Growth and mineral nutrition of field crops. 2.ed. New York: Marcel Dekker, 1997. 624p.

HANWAY, J.J.; WEBER, C.R. Dry matter accumulation in eight soybean soybean (Glycine max (L.) Merrill) varieties. Agronomy Journal, Madison, v.63, p.227-230, 1971.

HILU, K.W.; de WET, J.M.J. Domestication of Eleusine coracana. Economic Botany, New York, v.30, p.199-208, 1976.

LIMA, W.F.; TOLEDO, J.F.F.; ARIAS, C.A.A.; OLIVEIRA, M.F. Stability of soybean yield through different sowing periods. Pesquisa Agropecuária Tropical, Goiânia, v.35, n.11, p.21812189, 2000.

MASCARENHAS, H.A.A. Acúmulo de matéria seca, absorção e distribuição de elementos na soja, durante o seu ciclo vegetativo. 1972. 100f. Tese (Doutorado em Agronomia) Escola Superior de Agricultura "Luiz de Queiroz"-USP, Piracicaba, 1972.

MASCARENHAS, H.A.A. Acúmulo de matéria seca, absorção e distribuição de elementos, durante o ciclo vegetativo da soja. Campinas: IAC, 1973. 48p. (IAC. Boletim Técnico, 6)

MASCARENHAS, H.A.A.; BATAGLIA, O.C.; IGUE, T.; TISSELLI FILHO, O.; MIRANDA, M.A.C.; FERREIRA FILHO, A.W.P. Efeito residual de adubação na produção da soja. Campinas: IAC, 1981. 18p (Boletim Técnico, 24)
MASCARENHAS, H.A.A.; TANAKA, R.T. Soja. In: RAIJ, B.van; CANTARELLA, H.; QUAGGIO, J.A.; FURLANI, A.M.C. (Ed.). Recomendações de adubação e calagem para o Estado de São Paulo. 2.ed. Campinas: IAC, FUNDAG, 1997. p.202-203.

MORAES, R.N.S. Decomposição das palhadas de sorgo e milheto, mineralização de nutrientes e seus efeitos no solo e na cultura do milho em plantio direto. 2001. 90f. Dissertação (Mestrado em Agronomia) - Universidade Federal de Lavras, Lavras, 2001.

ODUORI, C.O. Small millets production and research in Kenya. In: RILEY, K.W.; GUPTA, S.C.; SEETHARAM, A.; MUSHONGA, J.N. Advances in small millets. New York: International Science, 1994. p.67-73.

PEIXOTO, C.P. Análise de crescimento e rendimento de três cultivares de soja em três épocas de semeadura e três densidades de plantas. 1998. 151f. Tese (Doutorado) - Escola Superior de Agricultura "Luiz de Queiroz"-USP, Piracicaba.

PEIXOTO, C.P.; CAMARA, G.M.S.; MARTINS, M.C.; MARCHIORI, L.F.S.; GUERZONI, R.A.; MATTIAZZI, P.Épocas de semeadura e densidade de plantas de soja: I. Componentes da produção e rendimento de grãos. Scientia Agrícola, Piracicaba, v.57, n.1, p.89-96, 2000.

PEDRINHO JÚNIOR, A.F.F.; BIANCO, S.; PITELLI, R.A. Acúmulo de massa seca e macronutrientes por plantas de Glycine max e Richardia brasiliensis. Planta Daninha, Viçosa, v.22, n.1, p.53-61, 2004.

REDDY, M.G.R.K.; REDDY, S.R.; REDDY, P.R.; SUBRAHMANYAM, K.; SUBRAHMANYAM, M.V.R. Effect of nitrogen on nitrogen and phosphorus uptake of fingermillet. Indian Journal of Agronomy, New Delhi, v.31, n.1, p.29-32, 1986.

ROSSI, C.; MONTEIRO; F.A. Parâmetros produtivos, nutrição em fósforo e atividade foliar da fosfatase ácida no capimbraquiária cultivado em solução nutritiva. Boletim da Indústria Animal, Nova Odessa, v.56, n.2, p.127-135, 1999.

SANTOS, H.P.; LHAMBY, J.C.B.; WOBETO, C. Efeito de culturas de inverno em plantio direto sobre a soja cultivada em rotação de culturas. Pesquisa Agropecuária Brasileira, Brasília, v.33, n.3, p.289-295, 1998.

SILVA, R.H.; ROSOLEM, C.A. Influência da cultura anterior e da compactação do solo na absorção de macronutrientes em soja. Pesquisa Agropecuária Brasileira, Brasília, v.36, n.10, p.1269-1275, 2001.

SUBBA RAO, A.; PRABHU, U.H. Effect of fertilizer and variety on nutritional quality of finger millet (Eleusine coracana) straw. Indian Journal of Agricultural Sciences, Dehli, v.66, n.4, p. 240-242, 1996.

TANAKA, R.T.; MASCARENHAS, H.A.A. Soja: nutrição, correção do solo e adubação. Campinas: Fundação Cargill, 1992. 60p. (Série Técnica, 7)

WERNER, J.C. Adubação de pastagens. Nova Odessa: IZ, 1986. 49p. (Boletim Técnico, 18)

WISNIEWSKI, C.; HOLTZ, G.P. Decomposição da palhada e liberação de nitrogênio e fósforo numa rotação aveia-soja sob plantio direto. Pesquisa Agropecuária Brasileira, Brasília, v.32, n.11, p.1191-1197, 1997. 